\title{
Internet Sites and Apps Available to Students Seeking Counselling, and What School Counsellors Should Know About Them
}

\author{
Brett Furlonger and Sonja Budisa \\ Monash University, Melbourne, Victoria, Australia
}

\begin{abstract}
Consumers are increasingly turning to both the internet and apps for mental health assistance. Mobile technologies such as smart phones and tablets offer swift and anonymous access for students to internet sites and app environments. Availability, however, does not guarantee quality or credibility. This web-based pilot study was undertaken to evaluate internet sites and apps on their ability to provide quality and credible information about counselling and counsellors. Of the 69 internet sites identified, only five met the inclusion criteria, and of the 30 apps identified, only eight met the inclusion criteria for quality and credibility. Inter-observer agreement was found to be $95.6 \%$ for the inclusion processes and $93 \%$ for quality and credibility. The findings strongly suggested that while there was a vast amount of information on the web, both internet sites and apps rarely met criteria for quality and credibility. The role of school counsellors in helping students use web-based counselling tools was discussed.
\end{abstract}

Keywords: internet, apps, counselling, school, students

The gold standard for counselling interventions in school situations has typically been one-to-one therapy. However, such labour intensive interventions often cannot meet the demand for psychological assistance required by school students, and so the mental health of school-aged students is at risk of deteriorating. It has been argued that there will never be enough trained professionals to meet the therapeutic needs of clients as people become confronted with increasingly more challenging problems and decisions (Jones et al., 2014; Shallcross, 2012). Indeed, there is a world average of only 10.3 mental health care workers per 100,000 people. The internet and mental health mobile apps have the potential to make up the shortfall in direct services as students can quickly and cheaply access information (Jones et al., 2014; Ybarra \& Suman, 2008). Significantly, there is an average of 85,473 mobile phone subscribers for every 100,000 people worldwide (Jones et al., 2014).

ADDRESS FOR CORRESPONDENCE: Brett Furlonger, Faculty of Education, Monash University, Clayton Campus, Clayton VIC 3800, Australia. Email: brett.furlonger@monash.edu 
Put another way, there are 1.5 billion internet users and 5.6 billion cell phone owners worldwide (International Telecommunications Union, 2011). In the United States alone, 91\% claim ownership of at least one cell phone (Raine, 2013). Smart phone use stands at $89 \%$ among young Australians, and a consumer survey in 2011 found that $24 \%$ of young people had a health app (including mental health apps) on their phone (Hides, 2014).

The advance in this form of technology is creating unprecedented opportunities for professionals to promote health behaviour (Dallery, Kurti, \& Erb, 2015). However, as a primary source of information, the internet has limitations, as not all the relevant information is easily found and much of it may not be of a good standard. Indeed, many school students do not question the sources of information they find and often make decisions to open a website based on the very short summaries provided (Brand-Gruwel, Wopereis, \& Walraven, 2009). It is, therefore, important for school counsellors to understand the search strategies and quality of information that school students might find when seeking help from a counsellor on the internet or from apps.

Help seeking can refer to the use of health and other services in the case of severe or serious mental health issues, including substance abuse, depression, and suicide ideation. Help seeking for young people often begins with the identification of a problem and the recognition that they cannot deal with it effectively by themselves (Fuller, Edwards, Procter, \& Moss, 2000; Vogel, Wester, Larson, \& Wade, 2006). It is clear that social norms play an important role in encouraging this behaviour (Rickwood, Deane, \& Wilson, 2007), and such behaviour can be defined as seeking assistance from an informal (e.g., parent or friend) or formal (e.g., counsellor or psychologist) source (Barker, 2007; Srebnick, Cauce, \& Baydar, 1996). Web-based tools could be categorised as an informal source of help.

\section{Driving With Google}

Although many search engines exist, Google has become the most popular of all, due largely to its retrieval speed (Taylor, 2005), even when words are spelt incorrectly (Jamali \& Asadi, 2010). Google's simplicity makes it astonishingly easy to use, utilising nothing more than a blank white page and a search box, but potentially leading to 'information overload' (Holscher \& Strube, 2000); in short, the user is presented with so much information to deal with, that it becomes difficult to manage (Snijders, Matzat, \& Reips, 2012). Although Google allows an abundance of information to be found quickly and easily, sorting through thousands of search results may present difficulties with acquiring relevant and precise information (Shadbolt \& Berners-Lee, 2008).

The need for users to search hundreds of pages of irrelevant search results prompted Google to develop a 'PageRank' system using a mathematical algorithm. This algorithm determines the importance of a page in terms of the importance of pages linking to it, and therefore determines the order of retrieved search results from most relevant to least relevant (Shadbolt \& Berners-Lee, 2008). This is determined by assigning a PageRank of 10 to a page that has a high probability of being accessed by a random internet user, and a 1 if it has a very low chance (Petrovic, 2011). Interestingly, the first page of results contains websites that have paid a 'placement fee' (Morahan-Martin, 2004). Fees can also be paid 
for 'AdWords' on a cost-per-click basis, where businesses are able to pay Google to have their website appear next to the search results when relevant keywords are searched (Smith, 2012). Although this helps these websites to build an online presence, most consumers are unaware of this practice (Morahan-Martin, 2004). Therefore, although the PageRank aims to simplify the search process and offer the most relevant search results, there is no filter that determines the quality of information (Cline \& Haynes, 2001).

Regular and skilled internet users are just as likely to experience searching difficulties because internet users do not have a definite research plan when seeking information about mental health issues or counselling (Brand-Gruwel, Wopereis, \& Vermetten, 2005; Fox \& Rainie, 2002). Consequently, retrieval results largely depend on whether searches are goal driven, with refined search terms, or data driven, with broader and less specific search terms. When the results of a search term are presented, the information is often scanned and decisions are made about which information may be useful (Brand-Gruwel et al., 2009). Unfortunately, many internet users do not go beyond the first page of results when searching for health information and often overlook 'indicators of credibility' when they access health websites (Morahan-Martin, 2004). Some of these indicators include evidence of author's details and credentials and evidence that a site is regularly updated and maintained (Cline \& Haynes, 2001). These are especially important as they have the potential to influence student decisions regarding their decisions about seeking help (Rains \& Karmikel, 2009). Health professionals and organisations often advise that online health information should not be a substitute for the experience and training that physicians encompass, yet there are individuals whose decisions have been both positively and negatively altered by the information they have sought through internet searching (Morahan-Martin, 2004; Powell \& Clarke, 2006). For example, there are those who use the internet to fill an information gap before visiting a health professional. In contrast, there are people who use internet health information to self-diagnose and treat medical conditions without consulting a doctor, overlooking indicators of quality and credibility (Morahan-Martin, 2004). As most online health information lacks peer review, the outcomes of such actions are sometimes unsatisfactory. Indeed, some self-selected medical interventions can be lethal. Sites selling counterfeit pills have a particularly poor reputation. Potentially, school students may find themselves in a similar situation when seeking mental health advice from internet sites that include information posted by unqualified or poorly credentialled individuals. Combine this fact with the knowledge that at last estimate, the number of North American citizens seeking health information from the internet ranged from 60 to 100 million (Grandinetti, 2000) and one gains an understanding of the need for consumer assistance to find credible sites.

Eysenbach and Kohler (2002) used a focus group to study how consumers seek credible sites by examining how internet users appraised health information websites. They found that authoritativeness, layout, advertising, readability, and currency were factors that influenced consumers' evaluation of quality and credibility. These factors are in line with those of Cline and Haynes (2001), who constructed criteria in response to concerns about websites advertising organisations that only 'looked credible'. Their 14 criteria were listed under five major headings: 'quality of health information', defined by standards as traditional information such as 
journals and universities; 'authoritativeness', defined by expertise and competence; 'trustworthiness', defined by a disclosure of a mission statement and a disclaimer about the sites limitations; 'message characteristics', defined by the currency and accuracy of the information; and 'audience characteristics' that were determined by the identification of the site's targeted consumer group and how well the content and design matched the targeted audience. However, such access tends to be hampered by design problems, technical language, and inaccuracies (Cline \& Haynes, 2001). To add to the challenge, it is clear that not all consumers check for credibility when sourcing information and assistance from internet websites.

\section{Captivated by Apps}

In addition to internet websites, newer technologies such as smart phones and tablets make it increasingly easy and likely that individuals will engage in information seeking through mental health apps. Mobile technology has had a profound impact on person-to-person communication and holds a wide appeal for students at all income levels. Indeed, the growth rate of mobile phone use has exceeded $4,000 \%$ in low-income countries and is assumed to be even more in counties with higher average income levels (Jones et al., 2014).

While mobile apps have been used to deliver psychosocial interventions, their use with individuals with severe mental illness is less well researched. Attempting to address this shortcoming, Depp et al. (2010) evaluated three forms of mobile interventions: an app designed to record patients' mood state and illness triggers; automated text messaging to collect data on psychotic symptom severity and social interactions, and adherence to prescribed pharmaceutical regimes; and a 'live therapist' link to increase compliance to homework. The authors consider that all three approaches met the 'proof-of-concept' stage, and the clients' adherence to the mobile interactions was close to those seen in other populations. Interestingly, although the three interventions were developed to be consistent with established psychosocial interventions, the authors were confident that novel interventions capturing the unique qualities of mobile devices were possible. For example, as mobile devices are 'context aware', data could be analysed in the client's environment, providing data on sleep/wake cycles and making it possible to link client-reported outcomes with biometric sensors such as GPS trackers and heart rate monitors. Indeed, a new health-care model that enables 'automated hovering' is needed (Asch, Muller, \& Volpp, 2012). Schroeder (2007) has claimed that as most health choices are made throughout the day, influencing these choices by using real-time monitoring provides the single biggest opportunity to improve health and reduce premature death.

Real-time support was evaluated by in a study of emotional self-awareness (Morris et al., 2010). Based on the assumption that self-awareness and selfregulation is intimately related to improving mental health, the researchers developed a mobile phone application that included a touch screen for mood reporting and therapeutic exercises designed to facilitate maladaptive thoughts and physical relaxation. Participants were able to report their emotional status and were able to access therapeutic exercises based on cognitive-behaviour therapy. The evidence suggested that the participants effectively applied the mood scales and therapeutic information that allowed them to effect meaningful change in their lives. Five case 
studies were used to assess participant prompts and the activation of therapies. Interviews revealed that the participants had increased levels of self-awareness and were able to self-reflect in weekly interviews. It was concluded that psychological interventions were delivered in a non-stigmatising manner to those who would not have easy access to therapy. Similarly, Edwards-Stewart (2012) describe an app to eliminate the loss of paper homework handouts and to make it easier for clients to integrate activities on personal calendars to manage their depressive episodes. Based on Lewinsohn's (1974) reinforcement theory of depression, it assumes that the condition can be treated by increasing the amount of participation in pleasant events. Lists of pleasant activities are included in the app that can be selected or generated randomly, which is then saved automatically in the client's calendar. Such features are assumed to assist the depressed and indecisive client, although there is yet no supporting empirical evidence for its effectiveness.

One of the most popular apps, MyFitnessPal (www.myfitnesspal.com/), assists people to manage their weight by allowing them to log the number of calories consumed and burned. It contains over 350 exercises and a food database of $3,282,000$ items. An advantage is that the digital calorie counter is more accurate than traditional self-report diaries and allows direct feedback and easy modification for individual users. However, if wi-fi is unavailable, exercise and food intake information cannot be logged. There is also considerable debate about whether counting calories is the most effective manner by which to manage weight loss. Calorie counting can also be detrimental to some people's mental health. Indeed, for those with eating disorders, MyFitnessPal can assist them to make increasingly restricted food choices (Young, 2013).

Other apps have doubtful value as health-related tools (Grohol, 2009). For example, the Blue-Light app claims that light in the $460-470 \mathrm{~nm}$ wavelength spectrum can be particularly effective in helping people with seasonal affective disorder (SAD). Theorised to help fight fatigue and drowsy driving, its effectiveness is based on both wavelength and the lux output (light received). The problem is the light required is between 398 lux to 1,350 lux for at least 30 minutes per day (and in some cases, much longer). The output for an iPhone $3 \mathrm{GS}$ is only 133, and 207 for a regular iPhone $3 \mathrm{G}$, which would require an exposure time of up to three times the amount to get the same benefits as reported by clinical trials. While there is clinical evidence that blue light in the $460-470 \mathrm{~nm}$ spectrum is helpful, it is quite a leap from these trials to suggest the same outcomes can be achieved on smart phones. No mention is made of this limitation prior to purchasing the app.

To date, mental health apps have tended to focus on those that encourage adherence to treatment, appointment reminders, and automated text messages following treatment (Hides, 2014). Regardless, students are captivated by smart-phone technology and the swiftly changing options for connection they provide. However, there is little in the literature to date that provides guidance for users seeking counselling support.

Accordingly, this article will summarise a pilot study investigating internet sites and free iPhone apps using replicable search strategy terms such as 'counsellor', 'counselling', 'counsellor online', 'counsellor Melbourne', and 'counselling relationship'. Using these terms, the aim was to discover what a typical student would find if they searched the internet using Google and apps for information about 
counselling, or assistance from a counsellor. This study also aimed to evaluate the quality and credibility of the information on each internet site and app in terms of providing information about counselling and counsellors.

\section{Method}

\section{Design}

The present study utilised an exploratory archival research method that analysed and categorised existing data. This method is maximally unobtrusive and yields the lowest possible degree of reactivity (L'Eplattenier, 2009; Conrad \& Maul, 1981). As a result, no ethical approval was required as all data was in the 'public domain'. All numbers related to 'site hits', and apps were those recorded at the time of writing.

\section{Materials}

A MacBook Pro and iPad Air were used to access internet sites and apps.

\section{Procedure}

This pilot study included four steps. The first step involved two searches, the first using Google.com.au. This was completed without logging out of either personal Gmail or YouTube accounts. Using the internet, a data-driven search was undertaken using only one word such as 'counsellor', followed by a goal-driven search that used at least two words such as 'counsellor relationship'. The second search was undertaken using the Apple App store only. It was decided to search for apps from the Apple App store as it is one of the four leading stores with over 3 billion downloads per quarter (Canalys, 2013). This was considered to be sufficient size for a representative sample. In the first step, five search terms were used in order to make the number of search engine count estimates (SECEs) manageable (Janetzko, 2008). The terms were 'counsellor', 'counselling', 'counsellor online', 'counsellor Melbourne' and 'counselling relationship'. Only the first page of results from Google were analysed as they had the most 'relevant' results, and research suggests that people usually do not look beyond this first page (Eysenbach \& Kohler, 2002; Morahan-Martin, 2004). The same search terms were used for apps. In the present study, only free apps were examined as it was thought that they would be the most likely first point of contact for school students.

The second step required two qualified reviewers to examine and evaluate the internet sites and apps according to the five-point criteria list below. Prior to examination, the criteria were discussed so each of the reviewers' evaluations would be as objective as possible. The third step involved an examination of the evaluation results and a calculation of the percentage agreement between the two reviewers. The final step included calculating SECEs and an examination of the categories of internet sites and apps.

\section{Quality and Credibility Appraisal}

Following the initial stage, an evaluation criteria for quality and credibility were selected, drawing on five of the fourteen criteria published by Cline and Haynes (2001) that were seen as appropriate for the sites and apps related to counselling. 
The goal of reducing the evaluation criteria to five was for purposes of everyday practicality. For example, the criterion providing 'evidence of monitoring links' to other sites for purposes of authoritativeness was not seen as particularly relevant. The response scale for each of the five criteria was 2-point (Yes/No). The first page of each site was then opened and evaluated in accordance with the following criteria:

1. Authoritativeness (also called competence or expertise) included an evaluation of an identified authorship with individual credentials, including educational qualifications and board certifications. Evidence-based information should be available with opportunities for feedback and interactivity through email.

2. Trustworthiness included an evaluation of the mission statement, number of 'sounds to good to be true' claims, and a disclaimer listing the site's limitations and scope. Conflicts of interest should be stated, particularly if a commercial sponsor is playing a role in site maintenance.

3. Message characteristics included an evaluation of site currency (i.e., last site updating), accuracy of information, readability, and intelligibility. The internet site or app should be presented in a logically organised fashion.

4. Audience characteristics included an evaluation of how well the site referred to targeted users (consumer compared to a professional) and how well the content and design matched the targeted audience.

5. Design features related to navigability that was defined as accessibility and ease of use of the site essential to finding information quickly. Unobtrusive backgrounds and legibility of text was preferred.

\section{Reliability of Data Coding}

Two reviewers were used to search and code both the internet and app data for purposes of reliability. Only internet sites and apps that met all five criteria were included in the evaluation. For the purposes of the present study, meeting five of the original fourteen criteria published by Cline and Haynes (2001) was considered the minimum standard for inclusion as a quality and credible site or app. Each reviewer was a trained and accredited counselling psychologist with experience using apps personally and professionally. Both reviewers had expertise working with adolescents. In the present study, a percentage agreement was selected as the approach to establishing reliability. Although there are more than 20 statistical measures to represent inter-assessor agreement (e.g., Berk, 1979; Suen \& Ary, 1989), a commonly used measure is a percentage agreement (or proportional agreement). Using the evaluation criteria, a percentage agreement was attained for the two reviewers who coded each internet site and app. The percentage agreement was calculated by dividing the total number of agreements by the total number of disagreements, plus agreements, and then multiplying by 100 (Cooper, Heron, \& Heward, 2007; What Works Clearing House, 2014). The documented agreements represented initial comparisons; all disagreements were discussed and resolved.

Study inclusion: Both reviewers assessed whether internet sites and apps met the inclusion criteria for quality and credibility following the two searches. Agreement was found to be $95.6 \%$ for the inclusion processes. 
Quality and credibility appraisal: The same two reviewers coded the eligible internet sites $(n=69)$ and apps $(n=132)$ against the evaluation criteria for quality and credibility. In this instance, interobserver agreement was $93 \%$, which exceeded the criteria ( $90 \%$ for an established measure) for reporting the same observed values after measuring the same events.

\section{Results}

The aims of the study were to discover what a typical school student would find if they used five search terms related to counselling on the internet and in the app environment and then to check for website and app credibility. The findings from the internet search are reported first.

\section{Internet Search}

Summary of aim 1 (internet sites): to discover what a typical student would find if they searched the internet using Google for information about counselling, or assistance from a counsellor. When the five terms were used for the internet, the numbers of hits per word (rounded) are as follows: 'counsellor' (16 million), 'counselling' (45 million), 'counsellor online' (11 million), 'counsellor Melbourne' $(475,000)$ and 'counselling relationship' (37 million). It is clear that a vast number of sites were found, as estimated by SECEs. It was curious that the term 'counselling relationship' provided the largest number of SECEs, reflecting perhaps the greatest need in the community. As predicted, when a third search term was added to 'counselling relationship' (i.e., counselling-relationship-marriage), the number of SECEs reduced from 37 million to 9 million. When any of the five terms were used, information about counselling clinics dominated the first page of search results. It is important, however, to remember that Google SECEs in the thousands and millions can be inaccurate, so the result presented above should be seen only as a guide to proportion of sites available per search word. Indeed, though the statistics bar may estimate that more than 1,000 results match a query, Google does not support more than 1,000 results for any query. Users can get to the 1000th or last result by setting individual user preferences to display 100 results or pages and clicking on the highest number or last ' 0 ' at the bottom of the results page (http://www.googleguide.com/last_results_page.html).

Interestingly, when each of the first pages was examined for each word term or terms, the site types fell into seven categories. The first were websites providing information about general counselling services. The second category included websites about counselling clinics and their contact details. The third category provided information about counselling education courses. The fourth provided online or phone counselling services, while the fifth posted information about professional counselling associations. The final two categories listed sites such as financial counselling and other forms of counselling irrelevant to mental health issues.

Summary of aim 2 (internet sites): to evaluate whether the quality and credibility of the information on each internet site was in terms of providing information about counselling and counsellors. Only the first pages were examined for credibility, as typically it is only the first page that consumers read. Consequently, using each of the five search terms, a total of 69 internet websites were identified, and in this 
TABLE 1

Displays the Number and Percentage of Internet Sites That Met Each Criterion for Quality and Credibility

\begin{tabular}{|c|c|c|c|c|c|}
\hline Criteria & Authoritativeness & Trustworthiness & $\begin{array}{l}\text { Message } \\
\text { characteristics }\end{array}$ & $\begin{array}{l}\text { Audience } \\
\text { characteristics }\end{array}$ & $\begin{array}{l}\text { Design } \\
\text { features }\end{array}$ \\
\hline $\begin{array}{l}\text { Sites meeting } \\
\text { separate } \\
\text { criteria }\end{array}$ & $25(17.2)$ & $23(15.9)$ & $20(13.8)$ & $30(20.7)$ & $18(12.4)$ \\
\hline
\end{tabular}

instance only 5 websites fitted all the five criteria for quality and credibility. Of the remaining 64 sites, the sites meeting any of the five individual criteria was less than $50 \%$ (see Table 1 ).

At the time of writing, an example of a website that met four of the five criteria was found at Reachout (www.reachout.com.au). Although the site did not meet the criteria for currency as a date did not appear on the website, regular updates and media stories were presented, and links to support (e.g., Lifeline) and real-time text chat were available. The website appeared on the first page of search results when using the search term 'counselling' and 'counsellor'. When the website was opened for examination, it provided a document or package that synthesised information that related to what counsellors do, acknowledged that different counsellors in different locations exist, and provided details about how an individual may feel about counselling. This package of information is objective as it does not state which type of counsellors are 'better'; rather, it states that counsellors use different approaches to help people solve various problems in their lives. Authorship details were provided along with the identification of the site's sponsor. The website was clearly and logically organised, making it easy to locate topics by either clicking on relevant tabs, such as 'wellbeing'. Additionally, there was also a search box in which search terms could be entered to assist in the location of related topics. There was no overt commercialism and the only advertisements were those that linked an individual to phone and online emergency helplines. Unfortunately, sites of this standard were not commonly found on the internet. An example of a site that did not meet criteria was Aashayer - The Hope (http://www.onlinecounselling4u.com/index.htm), a free online counselling service, which while providing a mission statement, a list of services and feedback interactivity, provides no information about the counsellors' qualifications or theoretical orientation. The site was also replete with irrelevant commercials for such items as t-shirts.

\section{App Search}

Summary of aim 1 (apps): To discover what a typical student would find if they searched the Apple App store for information about counselling, or assistance from a counsellor. It is clear that apps have a unique ability to assist users 'inthe-moment', by providing access when they would not normally have computer access. The majority of 134 free apps that appeared using the five search terms that were evaluated had this capability. Proportionally, the free apps accounted for a little over $80 \%$ of the available apps. While most of the fee-based apps were less 
TABLE 2

Number and Percentage of Apps Available By Search Word and Category

\begin{tabular}{llllr}
\hline & Therapist & Self-help & Support centres & Irrelevant \\
\hline Counsellor & $6(8.0)$ & $4(5.4)$ & $4(5.4)$ & $26(34.8)$ \\
Counselling & $3(4.0)$ & $12(16.1)$ & $1(1.3)$ & $63(84.4)$ \\
Counselling online & - & - & - & $2(2.7)$ \\
Counsellor Melbourne & - & - & - & - \\
Counselling relationship & - & $6(8.0)$ & - & $7(9.4)$ \\
\hline
\end{tabular}

TABLE 3

Displays the Number of Apps That Met Each Criterion for Quality and Credibility

\begin{tabular}{llllll}
\hline & & & Message & Audience & Design \\
Criteria & Authoritativeness & Trustworthiness & $\begin{array}{l}\text { characteristics } \\
\text { characteristics }\end{array}$ & features \\
\hline $\begin{array}{l}\text { Percentage of } \\
\begin{array}{l}\text { apps meeting } \\
\text { separate }\end{array}\end{array}$ & 67 & 15 & 10 & 72 & 45 \\
$\quad$ criteria & & & & \\
\hline
\end{tabular}

than $\$ 3.00$, some ranged as high as $\$ 24.99$. The number of free apps found by each search word is presented in Table 2. Only six applications were available to put a student in contact with a counsellor at a counselling centre. The self-help category, while not connecting a student with a counsellor, provided some guidance about how to improve or manage their mental health issues. Support centre apps included those that linked students with Youth Centres and Wellness centres that included counselling services. Irrelevant apps included fitness trackers, genogram creators, pharmaceutical sites, exam advice, and religious centres.

Summary of aim 2 (apps): to evaluate the quality and credibility of the information in Apple Apps in terms of providing information about counselling and counsellors. Based on the results it is evident that the majority of the apps were irrelevant to a student seeking a counsellor or information about counselling. The 30 apps that were identified as providing counselling support for students fell into three categories: therapist (direct link to a counsellor), self-help (advice and coaching for self-directed learning), and support centres (containing in-direct counsellor contacts and advice). The few apps that were relevant to counselling tended to be more credible than were the majority of internet websites (see Table 3) and had more information about the credentials of the counsellor and disclaimers, although apps were still inconsistent with regard to quality and credibility. Of the 30 apps that provided counselling support, only 8 apps met the five criteria for quality and credibility. Some of the app sites required students to volunteer private information before they were allowed into their website. For example, Couple Counseling (https://appsto.re/au/AO35W.i) promised to improve relationships but asked for a name and email address before allowing any progress into site details, raising concerns about credibility and security. The app Harmony Healing (https://appsto.re/au/U7jG5.i) offered untold possibilities and counselling among 
other therapies such as Reiki, massage, reflexology, and aromatherapy. For this site, the type of counselling offered had no detailed definition beyond that describing 'Reiki and therapeutic skills that lead to a better life'. Under the heading 'pricing', consumers were informed that one session cost $\$ 75$, with a $50 \%$ discount available for students and pensioners. On another page details were provided for the clinic's location and trading hours. No theoretical information was provided about the therapy or empirical evidence for the success of their counselling except that the performance of Reiki on patients receiving chemotherapy was described as fantastic. The counsellor's qualifications were listed as Reiki Master Level 3. Experience was itemised as working on a cruise ship for 3 years, volunteering in hospitals, and 10 years working in a beauty therapy college. As the app did not provide information on counsellor board certifications, made 'too good to be true' claims, and provided no information on currency it failed the first three criteria for quality or credibility.

\section{Discussion}

In this study, the aims were to assess the quality and credibility of internet sites and apps that a typical student might find if they used five specified counselling search terms. In particular, the content quality was evaluated using an instrument adapted from another study on the content quality and credibility of web-based consumer health information. Similar to the results reported in other studies (Abroms et al., 2013; Hides, 2014; Singer, Chatton, \& Khazaal, 2015) on mental health-related apps, the content quality was low in the present study. Most apps and internet sites were inadequately evidence based.

Another drawback to internet counselling sites was the fact that some of the links that appeared on the first page of a Google search may have been paid to appear, impacting on the credibility of the listed sites. A similar situation appears on Twitter where 'Tweet Trends' can also be bought, which, as with paid-forplacement Internet sites, threatens the validity of what users understand to be independent searches, a particular problem for students who only look at the first page following a Google search (Eysenbach \& Kohler, 2002). Consequently, it is crucial to the potential user that the quality and credibility of sites on the first page are accurately evaluated.

It was clear that those individuals who were using apps on the recommendation of their counsellor in a supportive environment still required some training so they become familiar with mobile devices (Depp et al., 2010). For students who explore the internet and app environment on their own, the risks of falling prey to poor web-based counselling advice and guidance are increased. The data from the present study certainly indicated that there are more substandard web-based counselling sites and apps than there are those with appropriate levels of quality and credibility.

Both counselling internet sites and apps were seen to be in an embryonic stage of development and tended to be interdependent with other components of mental health services such as counsellors. The most obvious examples of interdependence are those apps that can detect and store health status information remotely, such as physical activity or psychological states (Edwards-Stewart, 2012; Morris et al., 2010). These types of apps are designed to provide support for a variety 
of metal health issues such as severe mental illness (Depp et al., 2010), maintaining a healthy lifestyle, weight loss, and treatment for panic disorder (Singer et al., 2015). Although there are findings that suggest that web-based weight management programs are successful, at this point in time there is no empirical evidence for counselling apps improving educational or psychological outcomes for students.

Even though there are large gaps in services available to students, it is clear that accessing information by way of mobile technologies has widespread student appeal, and with $85 \%$ wi-fi coverage and 24-hour accessibility, a revolution in how mental health services are delivered has already begun. However, while apps are convenient, innovative and entertaining, most are currently limited in their scope and applicability for mental health, and few focus on the actual process of counselling. In turn, while internet sites generally contain more information, they also suffer shortcomings in the areas of quality and credibility. However, both technologies offer alternatives to a traditional office visit in a way similar to telephone and online counselling (Taylor \& Furlonger, 2011) but add to the mix easier access and sophisticated support for therapist interventions. With ease of use, however, come issues connected with security. When using counselling sites, consumers need to be aware that data posted on sites may not be secure and that their mobile device, if seen by others, may result in their diagnosis and other private information being disclosed (Depp et al., 2010). There have been recent attempts to improve security for consumers by systematising the access of existing apps through portals like The Toolbox (http://thetoolboxtest.au.reachout.com/) and beacon 2.0 (https://beacon.anu.edu.au/). These portals allow consumers to examine the opinions of a panel of experts who have reviewed and rated websites and mobile applications for mental and physical disorders.

Future investigations could match counselling internet sites and apps with actual clients to test out quality over time, as there is little data on the long-term adherence and acceptability of web-based counselling tools. An improved understanding of how clients use apps may be needed as there may be resistance to continual input of data; instead, a preference may be for app interventions that only require inputs of data over critical periods of time and then much lower levels of data input at other times (Depp et al., 2010).

\section{Limitations}

One of the obvious challenges involved in undertaking this form of research is the rate at which internet sites and apps develop and increase in number. The web's fluidity means that information dates quickly and sites and apps disappear and move without warning. Such rapid change renders measured scientific design, evaluation, projections, and dissemination challenging. Indeed, as the present study was undertaken, it was recognised that the rapidly changing internet and app environments tested the ability to research and publish before sites were obsolete, a problem Cline and Haynes (2001) have termed 'blurring the sense of present and future' (p. 686). It may be that new methods will need to be developed for the purposes of sampling web-based environments. It is also recognised that students may search the internet and apps using different terms. For example, the term 'help with depression' has a SECE of 215 million, illuminating the fact that a time-limited research project could not evaluate all sites. One suspects that school counsellors 
are also not in the position to review all sites or apps, adding strength to the need for a quality and credible guide for students. The use of a 5-point rating scale would have increased the scope and interpretability of the results. Finally, using only the Apple App store to search for relevant apps left the smaller Android market unreviewed.

\section{Recommendations}

There is a need for school counsellors to be aware that students are seeking mental health support from the internet and apps for reasons of convenience and anonymity. As these environments are often not reliable sources of information and guidance, school counsellors could play an important role in assisting students to navigate app and internet environments and demonstrating how the use of web-based mental health services can be used in conjunction with face-to-face counselling. School counsellors will need to develop critical web usership skills themselves in order to be able to judge not only the quality of information found, but to compare traditional versus online mental health information, with a view to improving the evaluation skills of school students.

\section{Conflicts of Interest}

The authors declare that the research was conducted in the absence of any commercial or financial relationships that could be construed as a potential conflict of interest.

\section{Acknowledgments}

We sincerely thank Kristian Lofhelm from the Monash University's Audio Visual and Educational Technology Office for his advice on internet searches.

\section{References}

Abroms, L.C., Lee Westmaas, J., Bontemps-Jones, J., Ramani, R., \& Mellerson, J. (2013). A content analysis of popular smartphone apps for smoking cessation. American Journal of Preventative Medicine, 45, 732-736. doi:10.1016/ j.amepre.2013.07.008

Asch, D.A., Muller, R.W., \& Volpp, K.G. (2012). Automated hovering in health carewatching over the 5000 hours. The New England Journal of Medicine, 367, 1-3.

Barker, G. (2007). Adolescents, social support and help-seeking behaviour. World Health Organization. Retrieved July 16, 2015, from http://whqlibdoc.who.int/ publications/2007/9789241595711_eng.pdf

Berk, R.A. (1979). Generalizability of behavioral observations: A clarification of interobserver agreement and interobserver reliability. American Journal of Mental Deficiency, 83, 460-472.

Brand-Gruwel, S., Wopereis, I.G.J.H., \& Vermetten, Y. (2005). Information problem solving by experts and novices: Analysis of a complex cognitive skill. Computers in Human Behavior, 21, 487-508.

Brand-Gruwel, S., Wopereis, I., \& Walraven, A. (2009). A descriptive model of information problem solving while using the Internet. Computers and Education, 53, 1207-1217. doi:10.1016/j.compedu.2009.06.004 
Canalys. (2013). 1\% quarterly growth in downloads for leading app stores. Retrieved July 14, 2013, from http://www.canalys.com/newsroom/11-quarterly-growthdownloads-leading-app-stores

Cline, R.J.W., \& Haynes, K.M. (2001). Consumer health information seeking on the internet: The state of the art. Health Education Research: Theory and Practice, 16, 671-692.

Conrad, E., \& Maul, T. (1981). Introduction to experimental psychology. New York: John Wiley and Sons.

Cooper, J.O., Heron, T.E., \& Heward, W.L. (2007). Applied behavior analysis (2nd ed.). Upper Saddle Creek, NJ: Prentice Hall.

Dallery, J., Kurti, A., \& Erb, P. (2015). A new frontier: Integrating behavioural and digital technology to promote health behaviour. Behaviour Analyst, 38, 19-49.

Depp, C.A., Mausbach, B., Granholm, E., Cardenas, V., Ben-Zeev, D., Patterson, T.L., Lebowitz, B.D., \& Jeste, D.V. (2010). Mobile interventions for severe mental illness: Design and preliminary data from three approaches. Journal of Nervous and Mental Disorders, 198, 715-721.

Edwards-Stewart, A. (2012). Using technology to enhance empirically supported psychological treatments. Positive activity jackpot. Medical Psychology, 60, 6066.

Eysenbach, G., \& Kohler, C. (2002). How do consumers search for and appraise health information on the world wide web? Qualitative study using focus groups, usability tests, and in-depth interviews. British Medical Journal, 324, 573-577

Fox, S., \& Rainie, L. (2002). Vital decisions: How internet users decide what information to trust when they or their loved ones are sick. Washington, DC: Pew Internet and American Life Project. Retrieved May 5, 2015, from http://www.pewinternet.org/Reports/2002/Vital-Decisions-A-Pew-Internet-HealthReport.aspx

Fuller, J., Edwards, J., Procter, N., \& Moss, J. (2000). How definition of mental health problems can influence help seeking in rural and remote communities. Australian Journal of Rural Health, 8, 148-153. doi:10.1046/j.1440-1584.2000.00303.x

Grandinetti, D.A. (2000). Doctors and the web: Help your patients surf the net safely. Medical Economics, 77, 186-188.

Grohol, J. (2009). Dubious Blue Light iPhone App. Psych Central. Retrieved July 13, 2009, from http://psychcentral.com/blog/archives/2009/08/21/dubious-bluelight-iphone-app/

Hides, L. (2014). Are SMART phone apps the future of youth mental health? In Psych. Retrieved July 14, 2015, from http://www.psychology.org.au/ Content.aspx? $\mathrm{ID}=5850$

Holscher, C., \& Strube, G. (2000). Web search behaviour of Internet experts and newbies. Computer Networks, 33, 337-346.

International Telecommunications Union. (2011). Retrieved July 14, 2015, from http://www.itu.int/em/ITU-D/Statistics/Pages/stat/default.aspx

Jamali, H.R., \& Asadi, S. (2010). Google and the scholar: The role of Google in scientists' information-seeking behaviour. Online Information Review, 34, 282-294. doi:10.1108/14684521011036990

Janetzko, D. (2008). Objectivity, reliability, and validity of search engine count estimates. International Journal of Internet Science, 3, 7-33. 
Jones, S.P., Patel, V., Saxena, S., Radcliffe, N., Al-Mari, A.A. \& Darzi, A. (2014). How Google's 'Ten things we know to be true could guide the development of mental health mobile health App'. Health Affairs, 33, 1603-1611.

L'Eplattenier. (2009). Opinion: An argument for archival research methods: Thinking beyond methodology. Urbana, 72, 67-80.

Lewinsohn, P.A. (1974). behavioural approach to depression. In R.J. Friedman \& M.M. Katz (Eds.), The psychology of depression: Contemporary theory and research psychology for depression (pp. 157-185). Washington, DC: Winston-Wiley.

Morahan-Martin, J.M. (2004). How Internet users find, evaluate, and use online health information: A cross-cultural review. Cyberpsychology and Behavior, 7, 497-510.

Morris, M.E., Kathawala, Q., Leen, T.K., Gorenstein, E.E., Guilak, F., Labhard, M., \& Deleeuw, W. (2010). Mobile therapy: Case study evaluations of a cell phone application for emotional self-awareness. Journal of Medical Internet Research, 12, e10. doi:10.2196/jmir.1371

Petrovic, D. (2011). How link value is determined by Google PageRank. Retrieved September 13, 2015 from http://dejanseo.com.au/how-link-value-is-determinedby-google-pagerank/

Powell, J., \& Clarke, A. (2006). Internet information-seeking in mental health. British Journal of Psychiatry, 189, 273-277. doi: 10.1192/ bjp.bp.105.017319

Raine, L. (2013). Cell phone ownership hits 91\% of adults. Pew Research Centre. Retrieved July 14, 2015, from http://www.pewresearch.org/fact-tank/2013/06/06/ cell-phone-ownership-hits-91-of-adults/

Rains, S., \& Karmikel, C.D. (2009). Health information-seeking and perceptions of website credibility: examining web-use orientation, message characteristics, and structural features of websites. Computers in Human Behavior, 25, 544-553. doi:10.1016/j.chb.2008.11.005

Rickwood, D.J., Deane, F.P., \& Wilson, C.J. (2007). When and how do young people seek professional help for mental health problems. Medical Journal of Australia, 187, S35-S39.

Schroeder, S.A. (2007). Shattuck lecture. We can do better-improving the health of the American people. The New England Journal of Medicine, 35, 1221-1228.

Shadbolt, N., \& Berners-Lee, T. (2008). Web science emerges. Information Technology, 299, 76-81.

Shallcross, L. (2012). What the future hold for the counselling profession. Counselling Today. Retrieved July 14, 2015, from http://ct.counseling.org/ 2012/03/what-the-future-holds-for-the-counseling-profession/

Singer, M.V., Chatton, A., \& Khazaal, Y. (2015). Quality of smartphone apps related to panic disorder. Frontiers in Psychiatry. Retrieved from http://journal.frontiersin.org/article/10.3389/fpsyt.2015.00096/full\#B54

Smith, N. (2012). Search tips from a Google ads expert. Business News Daily. Retrieved September, 13, 2015 from http://smallbusiness.foxbusiness.com/ marketingsales/2012/02/02/search-tips-from-google-ads-expert/

Snijders, C., Matzat, U., \& Reips, U. (2012). 'Big data': big gaps of knowledge in the field of Internet science. International Journal of Internet Science, 7, 1-5.

Srebnik, D., Cauce, A.M., \& Baydar, N. (1996). Help-seeking pathways for children and adolescents. Journal of Emotional and Behavioral Disorders, 4, 210-220. doi:10.1177/106342669600400402 
Suen, H.K., \& Ary, D. (1989). Analyzing quantitative behavioral observation data. Hillsdale, NJ: Erlbaum.

Taylor, N. (2005). Search me: the surprising success of Google. London: Cyan Publishing.

Taylor, W., \& Furlonger, B.E. (2011). A Review of vicarious traumatisation and supervision among Australian telephone and online counsellors. Australian Journal of Guidance and Counselling, 21, 225-235. doi:10.1375/ajgc.21.2.225

Vogel, D. L., Wester, S.R., Larson, L.M., \& Wade, N.G. (2006). An informationprocessing model of the decision to seek professional help. Professional Psychology: Research and Practice, 37, 398-406. doi:10.1037/0735-7028.37.4.398

What Works Clearing House (WWC). (2014, March). Procedures and standards handbook version 3 (p. E2). Retrieved July 14, 2015, from http://ies.ed.gov/ncee/wwc/pdf/ reference_resources/wwc_procedures_v3_0_standards_handbook.pdf

Ybarra, M., \& Suman, M. (2008). Reasons, assessments and actions taken: Sex and gender differences in uses of Internet health information. Health Education Research, 23, 512-521. doi:10.1093/her/cyl062

Young, C. (2013). MyFitnessPal Review: Pros and cons of top fitness app. Built Lean. Retrieved July 14, 2015, from http://www.builtlean.com/2013/09/19/ myfitnesspal-review/ 